\title{
DEVELOPMENT AND VALIDATION OF A MULTIDIMENSIONAL SCALE OF ENTREPRENEURIAL RISK PERCEPTION
}

\author{
SAULO D. BARBOSA \\ CERAG, Université de Grenoble II \\ 38000 GRENOBLE Cedex 9, France \\ JILL KICKUL \\ Miami University \\ MATTHEW LIAO-TROTH \\ Western Washington University
}

\section{INTRODUCTION}

Although risk has always been at the centre of the very definitions of words such as entrepreneur and venture, it has been frequently assessed in the entrepreneurship literature as a unidimensional construct. On the other hand, research on the psychology of decision making has increasingly shown that risk taking and risk perception are indeed multidimensional, context-dependent, and domain-specific (Hanoch, Johnson, \& Wilke, 2006; Hogarth, 1987; Slovic, Fischhoff, \& Lichtenstein, 1982; Weber, Blais, \& Betz, 2002).

Our purpose in this paper is to present a multidimensional scale designed to improve our assessment of risk perception in entrepreneurial settings, particularly the risk perception associated with the creation of a new venture. In doing so, we intend to clarify the concept of entrepreneurial risk perception and to shed some light on how different types of perceived risk may impact one's decision of starting a new business.

\section{BACKGROUND}

\section{Risk Perception and Entrepreneurial Decision Making}

Risk perception has been generally conceptualized as a decision maker's assessment of the risk inherent in a situation (Mullins \& Forlani, 2005; Sitkin \& Pablo, 1992) and has been conceived as a determinant of risk behavior and entrepreneurial decision making, i.e., risk perception has been assumed (and to some extent proven) to be negatively associated with risk behavior, risky decisions, and the decision to start a new business (Keh, Foo, \& Lim, 2002; Simon, Houghton, \& Aquino, 2000; Sitkin \& Pablo, 1992; Sitkin \& Weingart, 1995).

\section{Existing Measures}

Despite the existence of empirical evidence indicating the multidimensionality of risk, scholars in entrepreneurship continue to use unidimensional (sometimes single-item) measures of risk perception. Moreover, those measures generally capture only the downside of risk, i.e., the probability and magnitude of potential losses. As we shall argue, a more appropriate measure of entrepreneurial risk perception should also capture the probability and magnitude of potential gains.

\section{Development of a New Measure}

In order to develop a new measure of entrepreneurial risk perception, we draw upon existing conceptualizations of risk in general and entrepreneurial risk in particular. 
Expected utility and its variants. Most theoretical analyses of risky decisions depict each option as a gamble that can yield various outcomes with different probabilities. Albeit useful, such theories have a limited application in our study, first because of their assumption of probability-outcome independence, and second, because in this framework risk perceptions are generally not separately measured, or are simply ignored.

Entrepreneurial risk perception: risk as opportunity and risk as threat. One original conceptualization of entrepreneurial risk that departs from traditional models based on expected utility theory was presented by Dickson and Giglierano (1986). In their model, entrepreneurial risk has two components: the risk of failure (sinking-the-boat risk) and the risk of missing an opportunity (missing-the-boat risk). We propose an expansion of Dickson and Giglierano's ideas, by conceptualizing two types of risk: risk as threat and risk as opportunity.

Risk as threat corresponds to the general view of risk as (a) potential losses, (b) the magnitude of those losses, and (c) the uncertainty of those losses (as advanced by Mullins \& Forlani, 2005; Yates \& Stone, 1992). It also corresponds to the risk of failure, or sinking the boat, in Dickson and Giglierano's framework.

Risk as opportunity corresponds to the upside of risk, i.e., potential gains, their magnitude, and their uncertainty. Potential gains are, of course, the driving force pushing entrepreneurs towards action. Conceptualizing risk as opportunity, therefore, enables a better understanding of entrepreneurs' motivational factors, including especially notions such as regretful thinking (Markman, Balkin, \& Baron, 2002). In order to be consistent with previous literature, we believe that a general measure of entrepreneurial risk perception should include items referring to both gains and losses, or risk as opportunity and risk as threat.

A multidimensional measure of entrepreneurial risk perception. When we first generated the items for our scale, we started with the scale used by Simon et al. (2002). Since this scale refers to the case these authors used, we adapted all items to make them refer to the creation of a new venture in general. Then, since all items were framed in negative terms, i.e., capturing only risk as threat, we reformulated some items in order to let them reflect the degree to which respondents frame the creation of a new venture in positive terms, i.e., as an opportunity. Since those items seemed to capture the overall perceived risk of new venture creation, both in terms of opportunity and threat, we first labeled them 'overall.' In total, we generated eight items designed to assess the overall perceived risk associated with starting a new business: five items assessing risk as threat, three items assessing risk as opportunity.

Consistent with previous work using monetary gambles and monetary descriptions of ventures and decisions, the first specific area of risk perception we wanted to assess referred to financial risk. We generated five items to assess the financial dimension of risk perception: three of them framed as potential financial threats, two of them framed as potential monetary opportunities.

Consistent with conceptual frameworks that place the individual at the heart of entrepreneurship and as a key factor in the process of new venture creation (e.g., Bouchikhi, 1993; Bruyat, 1993; Bruyat \& Julien, 2000; Gartner, 1985; Sarason, Dean, \& Dillard, 2006), the second area of risk perception we addressed referred to personal risk. We developed five items to assess the personal dimension of entrepreneurial risk perception: again, three of them were framed as potential threats, while two of them presented potential positive outcomes.

Finally, the last dimension of risk perception we decided to assess came from the social component of the theory of planned behavior (Ajzen, 1991) and its applications in the entrepreneurship literature (e.g., Krueger \& Carsrud, 1993). Since the decision to start a new business is considerably influenced by the perceived social pressure to perform or not to 
perform an entrepreneurial behavior, it seemed logical to include a social dimension in our scale. Thus, we generated five items designed to assess the social dimension of risk perception in the entrepreneurial context of new venture creation. The complete scale we generated and tested is presented in the Appendix.

\section{METHODOLOGY}

\section{Participants}

Three hundred nine students that were enrolled in management courses at three different universities (127 men, 129 women, and 53 missing values) completed our new measure of entrepreneurial risk perception in a web-based survey. They also completed other measures that were collected in order to allow for cross-structure analysis (Pedhazur \& Schmelkin, 1991), providing empirical support for the external validity of our scale.

\section{Measures}

Entrepreneurial risk perception. Our measure of entrepreneurial risk perception consisted of 23 items in four risk domains: personal, social, financial, and overall (see Appendix). Responses were given along a 7-point Likert-type scale ( $1=$ Absolutely disagree; $4=$ neither agree or disagree; $7=$ Absolutely agree).

Risk preference. We assessed risk preference using the same measure found in the Panel Study of Entrepreneurial Dynamics (Reynolds, 2000).

Perceived behavioral control. The perceived behavior control measure was constructed based on the examples provided by Ajzen (2002) concerning the measurement of perceived controllability of behavior. Earlier version of this measure was used by Tkachev and Kolvereid (1999). The items included were: (1) If I wanted to, I could easily start and run a business. (2) I would have complete control over the situation if I start and run a business. (3) There are very few circumstances outside my control that prevent me from starting and running a business. (4) It is entirely up to me whether or not I start and run a business.

Responses were given along a 7-point Likert-type scale $(1=$ Absolutely disagree; $4=$ neither agree or disagree; 7 = Absolutely agree).

Entrepreneurial intention. Entrepreneurial intention was measured by 1 single item adapted from Krueger et al. (2000): "It is likely that I will start and run my own business in a near future." Responses were given along a 7-point scale ranging from 1=very unlikely to $7=$ very likely.

\section{ANALYSES AND RESULTS}

We conducted our analyses in two parts, in order to validate the internal structure of our measure of entrepreneurial risk perception and also assess its external validity. First, we proceeded to an internal-structure analysis using Lisrel VIII.

Within Lisrel, a factor analysis was conducted on both of the scales of risk as opportunity and risk as threat. The analyses were carried out using the covariance matrix. Model parameters were estimated using the maximum likelihood method. Although the chisquare score was significant, $\left(\chi^{2}(7, \underline{N}=309)=64.71, \underline{p}<.001\right)$, two incremental fit indexes, the comparative fit index (CFI) and the Incremental Fit index (IFI) were both .93. These 
indexes are independent of the size of the sample and degrees of freedom (Marsh, Balla, \& McDonald, 1988). Bentler and Bonett (1980) recommended that a value of .90 or higher on the CFI and IFI indicates an adequate fit of model to data. In addition, the CFI and IFI indicate relative improvement in fit of a hypothesized model over a null model. Figure 1 displays the Lisrel estimates of this factor analysis.

Insert Figure 1 about here

The second part of our analyses consisted in a cross-structure analysis, where we specified and tested two models in which both 'risk as opportunity' and 'risk as threat' were independent variables. First, we investigated risk preference on 'risk as opportunity' and 'risk as threat'. Second, we tested a global model in which 'risk as opportunity' and 'risk as threat' were not only the determinants of risk preference, but also explained perceived behavioral control and entrepreneurial intentions. Additionally, we also incorporated the role of start-up experience, given its role and influence on perceived behavioral control in previous research. Please see Figure 2 for an overview of the model and relationships.

Insert Figure 2 about here

This cross-structure model analysis also provides a more rigorous test of the proposed relationships and allows for better comparisons of differences between the two types of risks on constructs typically examined in models of entrepreneurial intentions. Aggregation was conducted for each common construct in order to have unidimensional composite scales for the structural models (Anderson \& Gerbing, 1988). In our initial tests, our overall model had a $\left.\chi^{2}(3, \underline{N}=309)=11.35, \underline{p}<.001 ; C F I=.98, I F I=.97\right)$

\section{DISCUSSION}

The internal structure of entrepreneurial risk perception. The results of our factor analysis indicate that indeed perceptions of risk as threat and risk as opportunity are not necessarily correlated, which is consistent with previous research showing that perceptions of opportunity and threat do influence risk taking, but are independent from each other (Krueger $\&$ Dickson, 1994). In addition, the results of our confirmatory factor analysis constitute strong evidence for the multidimensionality of both risk as threat and risk as opportunity. Thus, entrepreneurial risk perception is not only bidimensional (reflecting perceptions of threats and opportunities) but it is also domain specific, i.e., it has a financial component and also nonfinancial components, here represented by the personal and social dimensions.

Cross-structure analysis: risk perceptions as antecedents of risk preference, perceived behavioral control, and entrepreneurial intentions. As predicted, both perceptions of risk as threat and risk as opportunity influence significantly entrepreneurial intentions, but in opposite ways: perceptions of risk as opportunity tend to increase entrepreneurial intentions, whereas a view of risk as threat tends to decrease entrepreneurial intentions. These findings are consistent with Dickson and Giglierano's (1986) and also Venkataraman's (2002) suggestions that the fear of missing an opportunity may generate a bias toward action, accelerating the process of starting a new business, whereas the fear of failure tend to generate a bias toward planning and analysis, which refrains the passage to action and lowers entrepreneurial intentions.

In addition, our findings show that perceptions of risk as opportunity and threat also affect entrepreneurial intentions by influencing perceived behavioral control. Perceived behavioral control is a key variable in the theory of planned behavior and in entrepreneurial 
intentions models. It is related to perceptions of self-efficacy and judgments of feasibility, being also affected by cognitive heuristics such as 'illusion of control'. The causal relations between risk perception and perceived behavioral control need further research.

Finally, we also investigated the effects of perceptions of risk as opportunity and risk as threat on risk preference. Our findings - that risk preference is affected by perceptions of risk as opportunity but not significantly influenced by risk as threat - are consistent with Weber, Blais, and Betz's (2002) findings that preference is indeed more influenced by perceived benefits than perceived risks.

\section{REFERENCES AVAILABLE FROM THE AUTHORS}

\section{APPENDIX}

\section{A Multidimensional Scale of Entrepreneurial Risk Perception}

Please, indicate the extent to which you agree or not with the following statements:

Starting a new business is very risky. (O-)

Launching a new venture may have negative ramifications for my future career. (P-)

I see the possibility of starting a business as a potential loss. (O-)

I see the possibility of starting a business as a potential opportunity to pursue. $\left(\mathbf{O}^{+}\right)$

The probability of a new venture doing poorly is very high. (O-)

The financial amount one could lose by launching a new venture is substantial. (F-)

There is a great uncertainty when predicting how well a new venture will do. (O-)

In starting a new business, the chances to reap the financial benefits are quite high. $(\mathbf{F}+)$

The overall riskiness of a new venture is high. (O-)

Overall I would label the option of starting a business as something positive. ( $(\mathbf{O}+)$

Starting a new venture may have negative consequences for my professional life. (P-)

There is a high probability of a person losing respect from family and friends by starting his/her own business. (S-)

Starting my own business may have a positive impact on how my family and friends see me.

$(\mathbf{S}+)$

Starting a business may have a positive influence on my self-confidence. $(\mathbf{P}+)$

Starting a business may affect my personal life in a positive way. $(\mathbf{P}+)$

Launching a new venture may affect my social relationships in a very unpredictable way. (S-)

If I don't start my own business, I may be missing a great opportunity. ( $\mathbf{O}+)$

When starting a new venture, the chances of going bankrupt are very high. (F-)

When starting a new venture, the chances of becoming a millionaire are very high. $(\mathbf{F}+)$

Starting a business may affect my social life in a positive way. (S+)

Creating a new venture may have negative consequences for my relationships with family and

friends. (S-)

If I failed in starting a business, I would lose my self-esteem. (P-)

By launching a new venture, I would forgo other monetary opportunities. (F-)

Note: $\mathrm{O}=$ Overall, $\mathrm{P}=$ Personal, $\mathrm{F}=$ Financial, $\mathrm{S}=$ Social, $(-)=$ framed in negative terms (threat), $(+)=$ framed in positive terms (opportunity)

Items labelled as 'overall' were used as reflexive indicators for our latent variables 'risk as opportunity' (items labelled as $\mathbf{O}+$ ) and 'risk as threat' (items labelled as $\mathbf{O}-$ ). 
FIGURE 1

\section{Entrepreneurial Risk Perception}

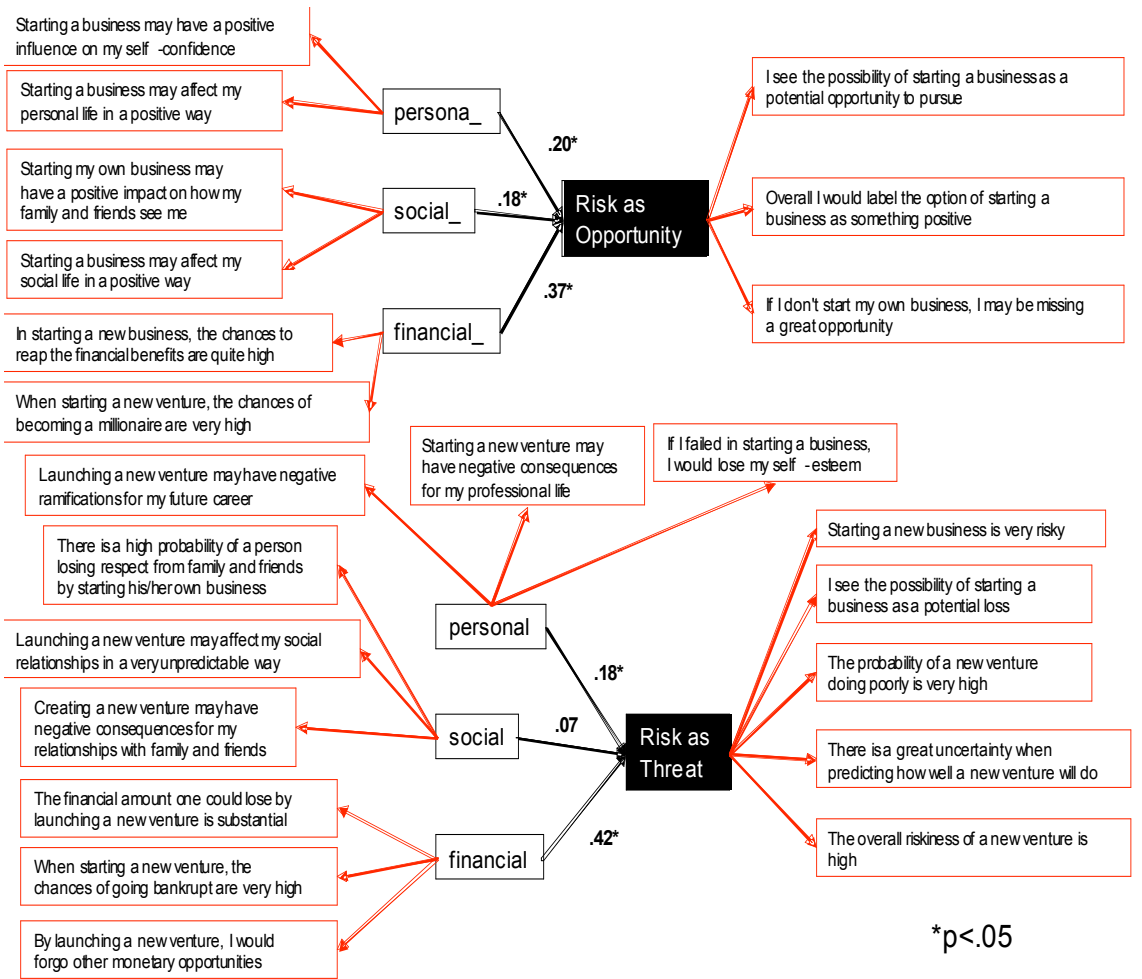

FIGURE 2

\section{Risk Preference and Intentions Model}

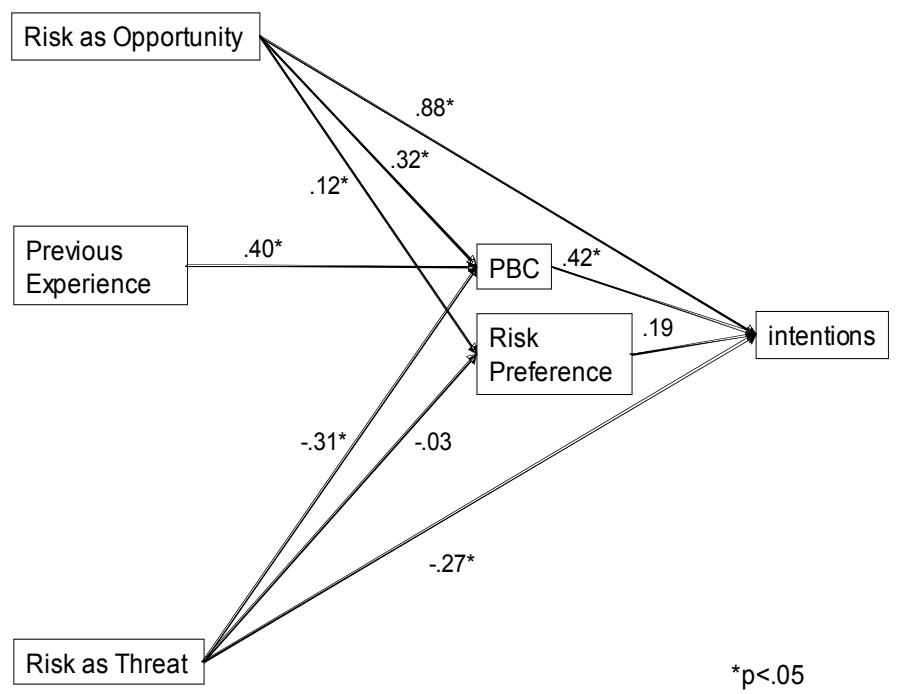


Copyright of Academy of Management Proceedings is the property of Academy of Management and its content may not be copied or emailed to multiple sites or posted to a listserv without the copyright holder's express written permission. However, users may print, download, or email articles for individual use. 
Copyright of Academy of Management Proceedings is the property of Academy of Management and its content may not be copied or emailed to multiple sites or posted to a listserv without the copyright holder's express written permission. However, users may print, download, or email articles for individual use. 
Copyright of Academy of Management Annual Meeting Proceedings is the property of Academy of Management and its content may not be copied or emailed to multiple sites or posted to a listserv without the copyright holder's express written permission. However, users may print, download, or email articles for individual use. 